\title{
ARTICLE \\ Role of nucleus accumbens core but not shell in incubation of methamphetamine craving after voluntary abstinence
}

\author{
Ludovica Maddalena Rossi ${ }^{1,2}$, Ingrid Reverte ${ }^{1,2}$, Davide Ragozzino ${ }^{1}$, Aldo Badiani (iD ${ }^{1,3}$, Marco Venniro iD $^{4}$ and Daniele Caprioli iD $^{1,2}$
}

\begin{abstract}
We recently introduced an animal model to study incubation of drug craving after prolonged voluntary abstinence, mimicking the human condition of relapse after successful contingency management treatment. Here we studied the role of the nucleus accumbens (NAc) in this model. We trained rats to self-administer a palatable solution (sucrose $1 \%+$ maltodextrin $1 \%, 6 \mathrm{~h} / \mathrm{day}$, 6 days) and methamphetamine ( $6 \mathrm{~h} /$ day, 12 days). We then evaluated relapse to methamphetamine seeking after 1 and 15 days of voluntary abstinence, achieved via a discrete choice procedure between the palatable solution and methamphetamine (14 days). We used RNAscope in-situ hybridization to quantify the colabeling of the neuronal activity marker Fos, and dopamine Drd1- and Drd2-expressing medium spiny neurons (MSNs) in NAc core and shell during the incubation tests. Next, we determined the effect of pharmacological inactivation of NAc core and shell by either $\mathrm{GABA}_{A}$ and $\mathrm{GABA}_{B}$ agonists (muscimol + baclofen, $50+50 \mathrm{ng} / \mathrm{side}$ ), Drd1-Drd2 antagonist (flupenthixol, $10 \mu \mathrm{g} / \mathrm{side}$ ), or the selective Drd1 or Drd2 antagonists (SCH39166, 1.0 $\mu \mathrm{g} / \mathrm{side}$ or raclopride, $1.0 \mu \mathrm{g} / \mathrm{side}$ ) during the relapse tests. Incubated methamphetamine seeking after voluntary abstinence was associated with a selective increase of Fos expression in the NAc core, but not shell, and Fos was colabeled with both Drd1- and Drd2-MSNs. NAc core, but not shell, injections of muscimol + baclofen, flupenthixol, SCH39166, and raclopride reduced methamphetamine seeking after 15 days of abstinence. Together, our results suggest that dopamine transmission through Drd1 and Drd2 in NAc core is critical to the incubation of methamphetamine craving after voluntary abstinence.
\end{abstract}

Neuropsychopharmacology (2020) 45:256-265; https://doi.org/10.1038/s41386-019-0479-4

\section{INTRODUCTION}

Despite decades of research on the neurobiological mechanisms of psychostimulant addiction, the only effective treatments are based on behavioral intervention strategies which harnesses operant principles to promote voluntary abstinence [1, 2]. One of these methods is contingency management, in which drug abstinence is reinforced and maintained via delivery of alternative incentives (e.g., monetary vouchers) [3]. However, when contingency management is discontinued most addicts relapse to drug use $[4,5]$.

At present, the brain mechanisms underlying relapse after cessation of contingency management are unknown. Based on the seminal studies of Lenoir et al., [6] and Ahmed et al., [7], showing that most rats prefer palatable food over cocaine in a discrete choice setting, we recently introduced a choice-based rat model of relapse after voluntary abstinence [8]. In this procedure, we first trained food-sated rats to self-administer palatable food (the alternative nondrug reward) and then methamphetamine for two weeks. We then assessed relapse to drug seeking at an early and late abstinence day. Between methamphetamine self-administration and the test on late abstinence day, rats were exposed to daily mutually exclusive choice sessions between the drug and palatable food [9]. Under these "contingency management" conditions, like human addicts, male and female rats choose to abstain from methamphetamine or heroin $[8,10,11]$. However, after discontinuing the palatable food, the rats' drug seeking response progressively increased during abstinence. This phenomenon, termed 'incubation of drug craving", was first observed after home cage forced abstinence conditions in rats trained to self-administer cocaine [12], and subsequently with other abused drugs $[13,14]$. Evidences of this phenomenon are also available in humans for nicotine [15], methamphetamine [16], alcohol [17, 18], and cocaine [19].

In our initial mechanistic characterization of the choice-based rat model of relapse, we identified: (1) a critical role of dopamine receptor 1-expressing (Drd1) neurons in the central amygdala $(\mathrm{CeA})$ and the glutamatergic projection from anterior insular cortex to CeA [20] in relapse to methamphetamine seeking after voluntary abstinence; (2) a critical role of dorsomedial striatum neuronal ensembles, in incubation of methamphetamine craving after voluntary abstinence [10]. In the current study, we assessed the role of nucleus accumbens (NAc) subregions (core and shell) in incubation of methamphetamine craving after food choiceinduced voluntary abstinence. Anatomically, the NAc core and shell are distinguished on the basis of the morphology and projections although both subregions are primarily constituted of two neuronal populations: dopamine receptors Drd1- and Drd2expressing medium spiny neurons (MSNs) that further differ in the neuropeptide expression profile [21].

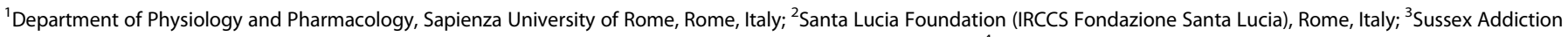

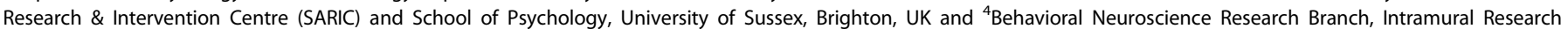
Program, Baltimore NIDA, NIH, Baltimore, MD, USA

Correspondence: Daniele Caprioli (daniele.caprioli@uniroma1.it)

Received: 17 March 2019 Revised: 3 August 2019 Accepted: 6 August 2019

Published online: 18 August 2019 
We studied the NAc core because previous studies showed that incubated cocaine craving after forced abstinence is associated with an altered firing in this area [22, 23]. Furthermore, incubated cocaine and methamphetamine craving after forced abstinence is reduced by inhibiting calcium-permeable AMPA receptor (CP-AMPARs) transmission in NAc core [24-26] or, for cocaine, via weakening the prelimbic cortex to NAc core pathway [27].

We studied the role of the NAc shell because, similarly to the core subregion, increased CP-AMPARs transmission is also evident after prolonged abstinence from cocaine self-administration [27-30]. Furthermore, incubated cocaine craving is reduced by selectively weakening the basolateral amygdala to NAc shell pathway [31], or simultaneous weakening of the infralimbic to Drd1-MSNs shell and ventral hippocampus to Drd1-MSNs shell pathways [32].

In the current study, we first used an RNAscope in situ hybridization (ISH) method used in our previous studies $[10,20,33]$ to determine whether incubation of methamphetamine craving is associated with activation of Drd1 and Drd2 in NAc core and shell, assessed by the activity marker Fos [34]. Next, we used site-specific reversible inactivation with $G_{A B A}$ and $\mathrm{GABA}_{\mathrm{B}}$ agonists (muscimol + baclofen [35]), Drd1-Drd2 antagonist (flupenthixol [36]), and selective Drd1 and Drd2 receptor blockade with SCH39166 [37] and raclopride [38] to determine the causal role of these receptors in NAc core and shell in incubation of methamphetamine craving after food choice-induced voluntary abstinence.

\section{MATERIALS AND METHODS}

Subjects, surgery (intravenous and intracranial), drugs, intracranial injections, RNAscope ISH assay, self-administration apparatus, procedures, palatable solution self-administration, methamphetamine self-administration, discrete choice procedure, voluntary abstinence, and relapse test: see Supplemental Online Material.

Our procedures followed the guidelines of the national law (DL 26/2014) on the use of animals for research based on the European Communities Council Directive (2010/63/UE), and were approved by the ethics committee of the Italian Ministry of Health (license/ approval ID \#: 705/2018-PR) and by the local Ethical Committee of the Santa Lucia Foundation.

\section{Specific experiments}

Experiment 1: Fos expression in NAc core and shell during relapse tests after voluntary abstinence. In experiment 1 (Exp. 1), we determined whether incubation of methamphetamine craving is associated with increased neuronal activity, as assessed by the activity marker Fos [39] in NAc core and shell. We also determined the cell type of the Fos-positive neurons in the two subregions by colabeling Fos with Drd1 and Drd2 [10, 20, 33, 40]. We used four groups of rats ( $n=3-5$ /group) in an experimental design that included the between-subject factors of test condition (no-test, relapse test) and abstinence day (days 1 and 15). The experiment consisted of three phases: training, discrete choice voluntary abstinence and relapse tests.

Training. We first trained rats to self-administer first the palatable solution (sucrose 1\%+maltodextrin 1\%; SM 1\%, $0.4 \mathrm{ml} /$ reward delivery; $6 \mathrm{~h} / \mathrm{d}, 6 \mathrm{~d})$ and then methamphetamine $(0.1 \mathrm{mg} / \mathrm{kg} /$ infusion; $0.1 \mathrm{ml} /$ infusion; $6 \mathrm{~h} / \mathrm{d}, 12 \mathrm{~d}$ ). The $\mathrm{SM} 1 \%$ solution delivery and the methamphetamine infusions were paired with the presentation of 20-s discrete light cues (triple light or white light, respectively).

Discrete choice procedure. We determined SM1\% versus methamphetamine choice after every three consecutive drug selfadministration sessions in all groups (three choice tests, during the training phase) and for 14 days (voluntary abstinence) preceding the abstinence day 15 relapse test.

Relapse tests. We tested the rats for methamphetamine seeking under extinction conditions on abstinence days 1 or 15 . The relapse tests were performed under extinction conditions in the presence of the house light. Active lever presses during testing, the operational measure of drug seeking in incubation of drug craving studies [13, 14], resulted in contingent presentations of the white light cue previously paired with methamphetamine, but not methamphetamine delivery. Immediately after the 60-min relapse tests, we anesthetized the rats and processed their brains for the RNAscope ISH assay. For the no-test rats, we brought them to the perfusion room from their home cage and perfused them on the same day and time as the relapse test rats. We matched the rats in the different groups for methamphetamine intake during the training phase.

Exp. 2: Effect of the NAc core or shell muscimol + baclofen $(M+B)$ inactivation on incubation of methamphetamine craving after voluntary abstinence

We performed intravenous surgeries on the rats and implanted them with bilateral guide cannulas $1 \mathrm{~mm}$ above the NAc core or shell (see SOM). The experimental procedure is identical to the one reported in Exp. 1, with the exception that we microinjected $M+B$ in NAc before the relapse tests. We also habituated the rats to the injection procedure for 3 days during the discrete choice procedure. We used eight groups of rats ( $n=6-8 /$ group) in an experimental design that included the between-subject factors of brain region (core, shell), abstinence day $(1,15)$, and muscimol + baclofen dose $(\mathrm{M}+\mathrm{B} ; 0,50 \mathrm{ng}+50 \mathrm{ng} / 0.5 \mu \mathrm{l} / \mathrm{side})$.

Relapse tests. We determined the effect of reversible inactivation of the NAc core and shell on extinction responding on abstinence days 1 or 15 . We injected bilaterally either vehicle (saline) or $M+B$ $(50 \mathrm{ng}+50 \mathrm{ng} / 0.5 \mu \mathrm{l} / \mathrm{side})$ into NAc core or shell $15 \mathrm{~min}$ before the 60 -min extinction test. Finally, to ensure that the effect of core inactivation by $\mathrm{M}+\mathrm{B}$ on extinction responding during the late withdrawal test was not due to motor deficits, we retrained 12 rats from the NAC core group to self-administer the SM1\% solution after they completed core injections and extinction tests on abstinence day 15 . We retrained them for 6 days $(6 \mathrm{~h} / \mathrm{d})$ for the $\mathrm{SM} 1 \%$ solution and then injected them vehicle or $\mathrm{M}+\mathrm{B}(50 \mathrm{ng}+$ $50 \mathrm{ng} / 0.5 \mu \mathrm{l} / \mathrm{side}$ ) into NAc core, $15 \mathrm{~min}$ before the 60 -min selfadministration session.

\section{Exp. 3: Effect of NAc core SCH39166 or raclopride injections on} incubation of methamphetamine craving

In Exp. 1, we found selective time-dependent increases in Fos expression in NAc core, but not in shell, and that Fos was colabeled with both Drd1 and Drd2. Moreover, in Exp. 2 we found a selective role of NAc core, but not shell. Based on these results, in Exp. 3 we determined the causal role of NAc core's dopamine receptors in the incubation of methamphetamine craving after food choice-induced voluntary abstinence. We used three groups of rats ( $n=6-8$ /group) in an experimental design that included the between-subject factors of drug condition (vehicle, SCH39166, raclopride). We excluded $n=2$ due to cannula's misplacement. The experiment procedure is identical to the one reported in Exp. 2 (see SOM).

Relapse tests. We tested rats for methamphetamine seeking under extinction conditions on abstinence day 15 . We injected either the Drd1 antagonist SCH39166 $(1.0 \mu \mathrm{g} / 0.5 \mu \mathrm{l} / \mathrm{side})$ or the Drd2 antagonist raclopride $(1.0 \mu \mathrm{g} / 0.5 \mu \mathrm{l} / \mathrm{side})$ into the core 15 -min before testing. The length of the test session was $60 \mathrm{~min}$. We matched the rats in the different groups for methamphetamine intake during the training phase. Finally, to verify that SCH39166 and raclopride, at 
the dose used in the relapse tests, do not non-selectively decrease operant responding, we retrained 21 rats after the day 15 testing to lever press for the SM1\% for $6 \mathrm{~h} / \mathrm{d}$. After 6 days of training sessions, we injected the rats with vehicle $(0.5 \mu \mathrm{l} / \mathrm{side}), \mathrm{SCH} 39166$ $(1.0 \mu \mathrm{g} / 0.5 \mu \mathrm{l} / \mathrm{side})$, or raclopride $(1.0 \mu \mathrm{g} / 0.5 \mu \mathrm{l} / \mathrm{side}) 10 \mathrm{~min}$ before the 60 -min self-administration session.

Exp. 4: Effect of NAc core flupenthixol injections on incubation of methamphetamine craving

In Exp. 3, we found that a reversible pharmacological inactivation of Drd1 or Drd2 MSNs in the NAc core decreased methamphetamine seeking during late (day 15) abstinence. In both cases we observed about $60 \%$ reduction of drug-seeking responding. Based on these results, in Exp. 4 we determined whether by inactivating both Drd1 and Drd2 MSNs with the Drd1-Drd2 antagonist cis-(Z)Flupenthixol dihydrochloride (flupenthixol) will cause total suppression of methamphetamine seeking on day 15 . In a separate group of rats we first determined the dose of flupenthixol, injected in the NAc core, that did not affect SM1\% solution-reinforced responding (see SOM).

We used two groups of rats ( $n=6-8 /$ group) in an experimental design that included the between-subject factor of dopamine antagonist condition (vehicle, flupenthixol). We excluded two rats due to cannula's misplacement. The experiment procedure is identical to the one reported in Exp. 2 (see SOM).

Relapse tests. We tested rats for methamphetamine seeking under extinction conditions on abstinence day 15 . We injected either vehicle or flupenthixol $(10 \mu \mathrm{g} / 0.5 \mu \mathrm{l} / \mathrm{side})$ into the core 15 -min before testing. The length of the test session was $60 \mathrm{~min}$. We matched the rats in the different groups for methamphetamine intake during the training phase.

\section{Statistical analysis}

Behavioral data. We analyzed the data with the statistical program SPSS Statistics using GLM module (IBM, version 23). For the self-administration training, we analyzed the amount of SM1\% solution rewards and methamphetamine infusions separately with a repeated-measures ANOVA, using the within-subjects factor of session. For the choice sessions during the training phase and the food choice-induced voluntary abstinence we analyzed the data with a repeated-measures ANOVA, using the within-subjects factors of reward type (SM1\% solution or methamphetamine) and choice session.

For the relapse test in Exp. 1 we analyzed active lever pressing using one-way ANCOVA with the between-subjects factor of abstinence day (1 or 15), and we included the inactive lever presses as covariate. For the relapse test in Exp. 2, we analyzed data using the between-subjects factors of abstinence day (1 or $15)$ and $M+B$ dose $(0$ or $50+50 \mathrm{ng})$. For the relapse tests in experiment 3-4, we used one-way ANCOVA with the betweensubjects factors of dopamine antagonist condition (Exp. 3: vehicle, SCH39166, raclopride; Exp. 4: vehicle, flupenthixol) and the inactive lever presses were included as a covariate. For Exps. 2, 3 , and 4, we also used a mixed ANOVA to analyze the 60-min time course of active lever responding for day 15 , using the betweensubjects factor of drug condition and the within-subjects factor of session minutes $(20,40$, and 60$)$. For the dose effect curve of flupenthixol, we analyzed the data using a repeated-measures ANOVA with the within-subject factor of flupenthixol dose $(0,10$, 20,30 , and $40 \mu \mathrm{g}$ ) and the least significant-difference test for multiple comparisons.

RNAscope and immunohistochemistry data. In Exp. 1 we analyzed the data with the between-subjects factors of abstinence day (1 or 15) and test condition (test or no-test).

In the Supplementary Online Material (SOM) we offer a summary of the statistical analysis. In the figures we only report significant effects that are critical for data interpretation. We followed up on significant main and interaction effects $(p<0.05)$ using Fisher PLSD post hoc tests.

\section{RESULTS}

Exp. 1: Fos expression in NAc core and shell during relapse tests after voluntary abstinence

The timeline of Exp. 1 is shown in Fig. 1 a.

SM1\% and methamphetamine training. The rats increased the rewards intake over sessions (Fig.1b) and extended daily access $(6 \mathrm{~h} /$ day) to methamphetamine led to escalation of drug intake $[8,10]$. The statistical analysis showed a significant effect of session for SM1\% solution $\left(F_{5,75}=21.903, p<0.001\right)$ and methamphetamine $\left(F_{11,165}=20.5, p<0.001\right)$. During the three discrete choice sessions, the rats showed a strong preference for the SM1\% solution $\left(F_{1,15}=164.2, p<0.001\right.$; Fig. $\left.1 c\right)$.

Voluntary abstinence. During the 14 days of food choice-induced abstinence the rats showed a strong preference for the SM1\% solution, with an almost complete suppression of the methamphetamine self-administration during the voluntary abstinence (Fig. 1d). The statistical analysis showed a significant effect of reward type $\left(F_{1,7}=259.1, p<0.001\right)$.

Relapse test. Methamphetamine seeking in the extinction tests was higher at abstinence day 15 than after 1 abstinence day, demonstrating incubation of methamphetamine craving after voluntary abstinence (Fig. 1e). The ANCOVA of active lever presses (inactive lever as covariate) showed a significant effect of abstinence day $\left(F_{2,7}=87.4, p<0.001\right)$.

Fos and Fos + Drd1 or Drd2 RNAscope double-label data. Representative pictures of Fos/Drd1/Drd2 triple labeling by RNAscope $\mathrm{ISH}$ are shown in Fig. 1f. Fos expression in the relapse test was higher at abstinence day 15 relative to abstinence day 1 in NAc core but not in NAc shell (Fig. 1g). The statistical analysis, which included the between-subjects factors of abstinence day and test condition showed a main effect of both factors and the interaction between them for NAc core [abstinence day $\left(F_{1,12}=21.1, p=\right.$ $0.001)$; test $\left(F_{1,12}=25.2, \quad p<0.001\right)$; abstinence day $X$ test interaction $\left.\left(F_{1,12}=13.5, p=0.003\right)\right]$. We found no evidence for cell-type specificity of the activated (Fos-positive) NAc core neurons on abstinence day 15 (Fig. 1h, i upper and lower panels; for statistics refer to Supplementary Table 1).

Exp. 2: Effect of the NAc core or shell muscimol + baclofen $(M+B)$ inactivation on incubation of methamphetamine craving The timeline of the experiment is shown in Fig. 2a.

SM1\% solution and methamphetamine training. The rats increased the rewards intake over sessions (Fig. 2b). The statistical analysis showed a significant effect of session for SM1\% solution $\left(F_{11,250}=\right.$ 52.6, $p<0.001)$ and methamphetamine $\left(F_{11,550}=81.2, p<0.001\right)$. During the three discrete choice sessions the rats showed a strong preference for the SM1\% solution over methamphetamine that increased over time [session $\left(F_{2,100}=6.6, p<0.01\right)$ : reward $\left(F_{1,50}=76.5, p<0.001\right)$; reward $X$ session $\left(F_{2,100}=9.3, p<0.001\right.$; Fig. 2c)]. We did not observe differences between groups.

Voluntary abstinence. During the 14 days of food choice-induced voluntary abstinence the rats showed a strong preference for the SM1\% solution, with an almost complete suppression of methamphetamine self-administration during the voluntary abstinence that increased over time (Fig. 2d). The statistical analysis showed a significant effect of reward type $\left(F_{1,26}=596.7, p<0.001\right)$ and session $\left(F_{13,338}=3.7, p<0.001\right)$, and the interaction reward $\mathrm{X}$ session $\left(F_{13,338}=2.3, p<0.01\right)$. 
$\mathrm{SM} 1 \% \mathrm{SA}$

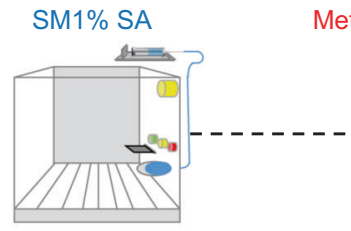

6 days
Methamphetamine SA

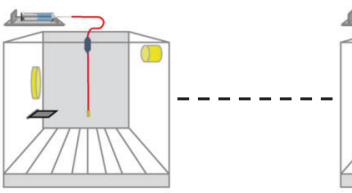

12 days +

3 choice sessions
A. Timeline Exp. 1

Relapse test

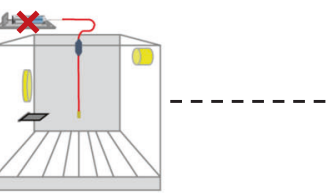

Day 1

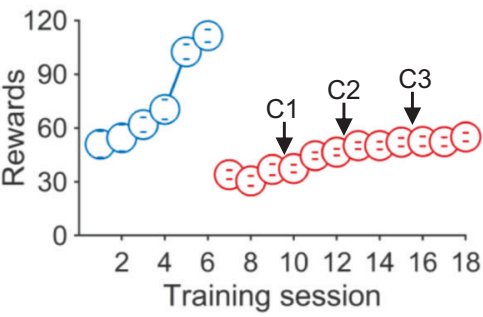

C. Choice test

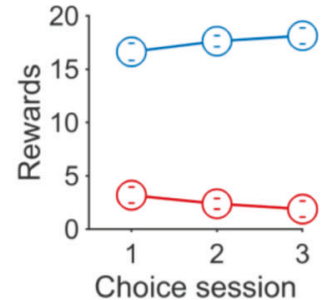

D. Voluntary abstinence

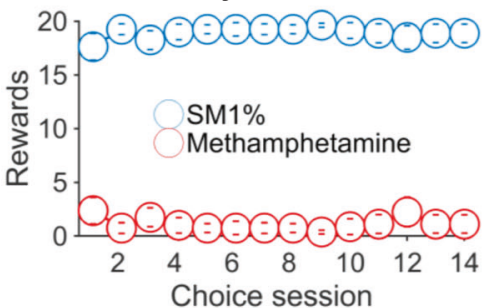

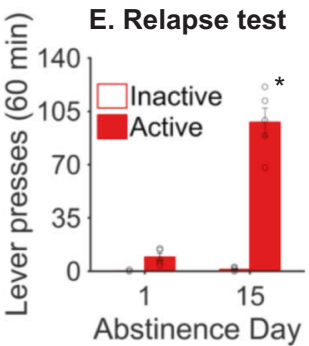

Relapse test

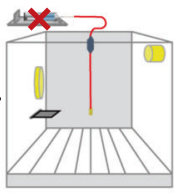

Day 15

F. Fos expression in Drd1 and Drd2 positive cells in Nucleus Accumbens
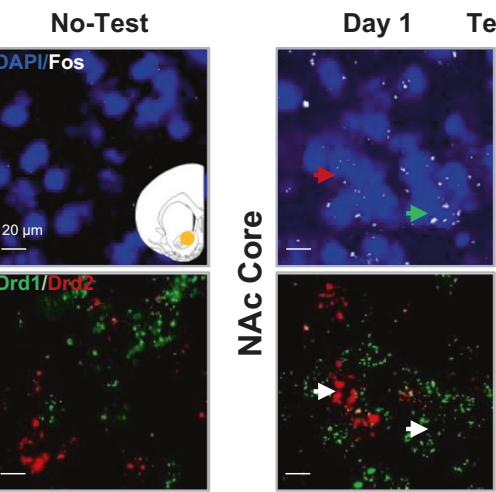

Day 15

No-Test
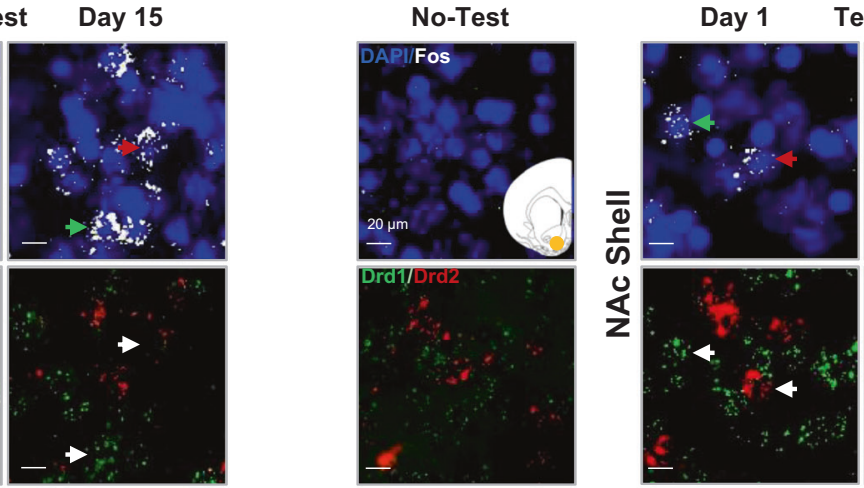

Test Day 15

G. Fos neurons quantification
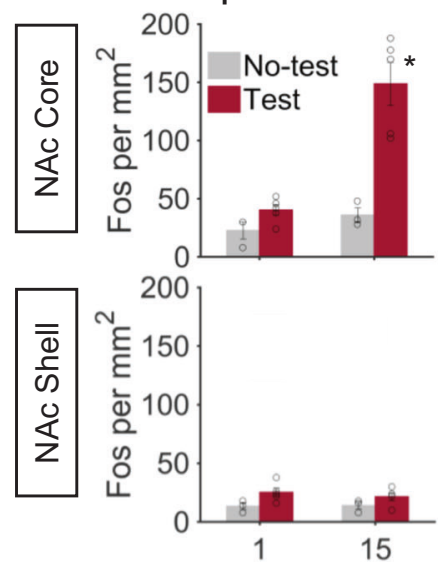

Abstinence Day
H. Double-labeled cells (Drd1/Fos)

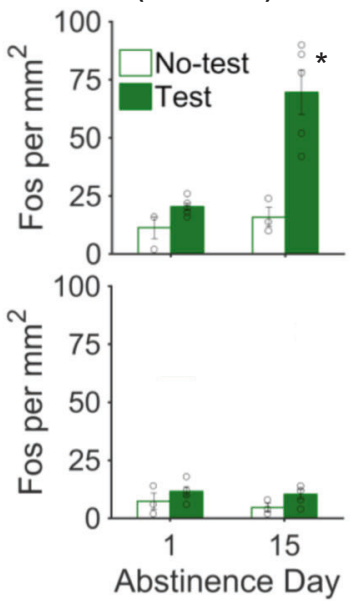

I. Double-labeled cells (Drd2/Fos)

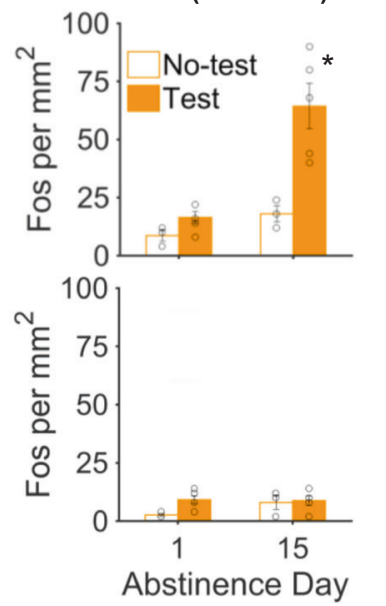

Relapse test. NAc core injections of $\mathrm{M}+\mathrm{B}$ decreased methamphetamine seeking in the extinction tests on abstinence day 15 but not abstinence day 1 (Fig. 2e). The statistical analysis, which included the between-subjects factors of abstinence day and $M+$ $B$ dose, showed a main effect of the abstinence day $\left(F_{1,22}=27.2\right.$, $p<0.001), \mathrm{M}+\mathrm{B}$ dose $\left(F_{1,22}=19.7, p<0.001\right)$ and interaction of abstinence day $X M+B$ dose $\left(F_{1,22}=13.6, p=0.001\right)$. In contrast, shell injections of $M+B$ had no effect on methamphetamine seeking in the extinction tests at abstinence day 15 and abstinence day 1 (Fig. 2f).

We also analyzed the time course of extinction responding on abstinence day 15 using the between-subject factors NAc subregion and $M+B$ dose, and the within-subject factor session time (20,40, and $60 \mathrm{~min}$; Fig. 2g). The statistical analysis showed a 
Fig. 1 Incubation of methamphetamine craving is associated with activation of NAc core but not shell: behavioral data and RNAscope data. a Timeline of the experiment (Exp.1). The self-administration chamber is equipped with two active levers (SM1\% and methamphetamine), one inactive lever, one discriminative stimulus (yellow house light), two conditioned stimuli (white light for methamphetamine, triple light for SM1\%), two pumps (one for SM1\%, one for methamphetamine), and a liquid receptacle. b Self-Administration training. Mean \pm SEM number of $\mathrm{SM} 1 \%$ rewards $(0.4 \mathrm{ml} /$ reward) or methamphetamine infusions $(0.1 \mathrm{mg} / \mathrm{kg} /$ infusion; $0.1 \mathrm{ml} /$ infusion) during the $6-\mathrm{h}$ sessions, $n=16$. C1, C2 and C3 refer to the choice sessions performed during training (data shown in panel c). c Choice sessions during training. Mean \pm SEM number of $\mathrm{SM} 1 \%$ rewards and methamphetamine infusions earned during the three discrete choice sessions during training (20 trials every 10 min), $n=16$. d Voluntary abstinence. Mean \pm SEM number of SM1\% rewards and methamphetamine infusions earned during 14 discrete choice sessions, $n=10$. e Relapse tests. Mean \pm SEM number of lever presses on active, non-reinforced, and inactive levers during the 60 -min test sessions. $\mathbf{f}$ Representative photomicrographs of the NAc core and NAc shell and Fos and Drd1 or Drd2 labeling in the relapse-test and no-test groups. (Fos, white; Drd1, green; Drd2, red; DAPI, blue). Arrows indicate representative cells. g Fos neurons quantification. Number of Fos-IR (immunoreactivity) nuclei per $\mathrm{mm}^{2}$ in NAc core (top panel) and shell (bottom panel). $\mathbf{h}$ Fos-IR coexpression with Drd1 cells in NAc core (top panel) and shell (bottom panel). i Fos-IR coexpression with Drd 2 cells in NAc core (top panel) and shell (bottom panel). ${ }^{*} p<0.05$ different from day 1 . Circles represent individual data, $n=16,3-5 /$ group

main effect of $M+B$ dose $\left(F_{1,27}=16.2, p<0.001\right)$, session time $\left(F_{2,27}=28.6, p<0.001\right)$, NAc subregion $\left(F_{1,27}=9.3, p<0.01\right)$, and interaction between the $\mathrm{M}+\mathrm{B}$ dose and $\mathrm{NAc}$ subregion $\left(F_{1,27}=\right.$ $6.4, p<0.05)$

Finally, to rule out that the NAc core effect was due to a motor deficit, we trained all the NAc core abstinence day 15 group to self-administer SM1\% solution (Fig. S2B). We then determined the effect of vehicle or $M+B$ injections into the NAc core on ongoing SM1\% solution-reinforced responding. We found that $M+B$ injections into NAc core had no effect on $\mathrm{SM} 1 \%$ solution selfadministration $\left(F_{1,9}=0.2, p=0.6\right)$ (Fig. $\left.\mathrm{S} 2 \mathrm{C}\right)$.

Exp. 3: Effect of NAc core SCH39166 or raclopride injections on incubation of methamphetamine craving

The timeline of the experiment is shown in Fig. 3a.

SM1\% solution and methamphetamine training. The rats increased the rewards intake over sessions (Fig. S1B, left panel). The statistical analysis showed a significant effect of session for SM1\% solution $\left(F_{5,100}=31.9, p<0.001\right)$ and methamphetamine $\left(F_{11,220}=25.0, \quad p<0.001\right)$. During the three discrete choice sessions, the rats showed a strong preference for the SM1\% solution $\left(F_{1,20}=40.8, p<0.001\right)$ (Fig. S1B, right panel).

Voluntary abstinence. During the 14 days of food choice-induced abstinence the rats showed a strong preference for the SM1\% solution (Fig. 3b). The statistical analysis showed a significant effect of reward type $\left(F_{1,20}=2611.2, p<0.001\right)$.

Relapse test. NAc core injections of raclopride or SCH39166 decreased methamphetamine seeking in the extinction tests at abstinence day $15\left(F_{2,17}=4.3, p<0.05\right.$; main effect of dopamine antagonist condition) (Fig. 3c). We also analyzed the time course of extinction responding using the between-subjects factor of dopamine antagonist condition and the within-subjects factor of session (20, 40, and $60 \mathrm{~min}$; Fig. 3d). The statistical analysis showed a main effect of the dopamine antagonist condition $\left(F_{2,18}=5.5, p<\right.$ $0.05)$, session time $\left(F_{2,36}=31.3, p<0.001\right)$ and an interaction between the dopamine antagonist condition and session time $\left(F_{4,36}=6.6, p<0.001\right)$.

Finally, to rule out that the effect was due to a motor deficit, we trained all the rats to self-administer SM1\% solution (Fig. S2D) and determined the effect of injections into the NAc core on ongoing SM1\% solution-reinforced responding. We found that raclopride or SCH39166 injections into NAc core had no effect on SM1\% solution self-administration $\left(F_{2,17}=0.2, p=0.8\right)$ (Fig. S2E).

Exp. 4: Effect of NAc core flupenthixol injections on incubation of methamphetamine craving

The timeline of the experiment is shown in Fig. 3a.

SM1\% solution and methamphetamine training. The rats increased the rewards intake over sessions (Fig. S1C, left panel).
The statistical analysis showed a significant effect of session for SM1\% solution $\left(F_{5,65}=2.620, p<0.05\right)$ and methamphetamine $\left(F_{11,143}=3.422, \quad p<0.05\right)$. During the three discrete choice sessions, the rats showed a strong preference for the SM1\% solution $\left(F_{1,13}=10.3, p<0.01\right)$ (Fig. S1C, right panel).

Voluntary abstinence. During the 14 days of food choice-induced abstinence, the rats showed a strong preference for the SM1\% solution (Fig. 3e). The statistical analysis showed a significant effect of reward type $\left(F_{1,13}=82.9, p<0.001\right)$.

Relapse test. NAc core injections of flupenthixol decreased methamphetamine seeking in the extinction test at abstinence day $15\left(F_{1,12}=7.3, \quad p=p<0.05\right.$; main effect of dopamine antagonist condition) (Fig. 3f). We also analyzed the time course of extinction responding using the between-subjects factor of dopamine antagonist condition and the within-subjects factor of time (20,40, and $60 \mathrm{~min}$; Fig. 3g). The statistical analysis showed a main effect of Time $\left(F_{2,24}=13.0, p<0.001\right)$.

The timeline of the dose effect curve of flupenthixol is shown in Fig. S3A.

SM1\% solution training. The rats increased the rewards intake over sessions (Fig. S3B). The statistical analysis showed a significant effect of session for SM1\% solution $\left(F_{4,24}=9.0, p<0.01\right)$.

Dose effect curve. Flupenthixol dose dependently decreased $\mathrm{SM} 1 \%$ solution reinforced responding (Fig. S3C). The statistical analysis showed a significant effect of dose $\left(F_{4,24}=8.7, p<0.01\right)$. A post hoc analysis conducted with the least significant-difference test revealed a significant difference between saline and the doses of flupenthixol of 30 and $40 \mu \mathrm{g} / \mathrm{side}$ and a nearly significant effect at the dose of $20 \mu \mathrm{g} / \mathrm{side}$.

\section{DISCUSSION}

There are three main findings in our study. First, incubation of methamphetamine craving was associated with increased Fos expression in NAc core Drd1- and Drd2-MSNs after 15 abstinence days; in contrast we did not found any increased Fos expression in the NAc shell subregion. Second, reversible inactivation of NAc core selectively decreased methamphetamine seeking during late (day 15) but not early (day 1) abstinence. This effect was selective to methamphetamine seeking, muscimol + baclofen injections had no effect on $\mathrm{SM} 1 \%$ solution-reinforced responding test. Third, blockade of Drd1-, Drd2- or both Drd1-Drd2-family receptors in NAC core decreased incubated (day 15) methamphetamine craving after voluntary abstinence to a similar extent. Together, our results indicate that dopamine transmission through Drd1 and Drd2 in activated NAc core is critical to the incubation of methamphetamine craving after food choice-induced voluntary abstinence. 
A. Timeline Exp. 2

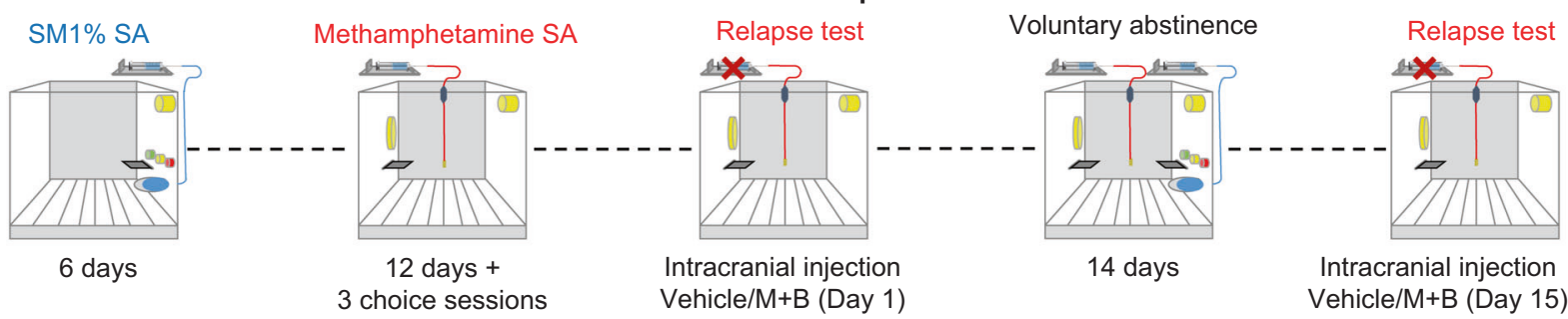

B. Self-administration
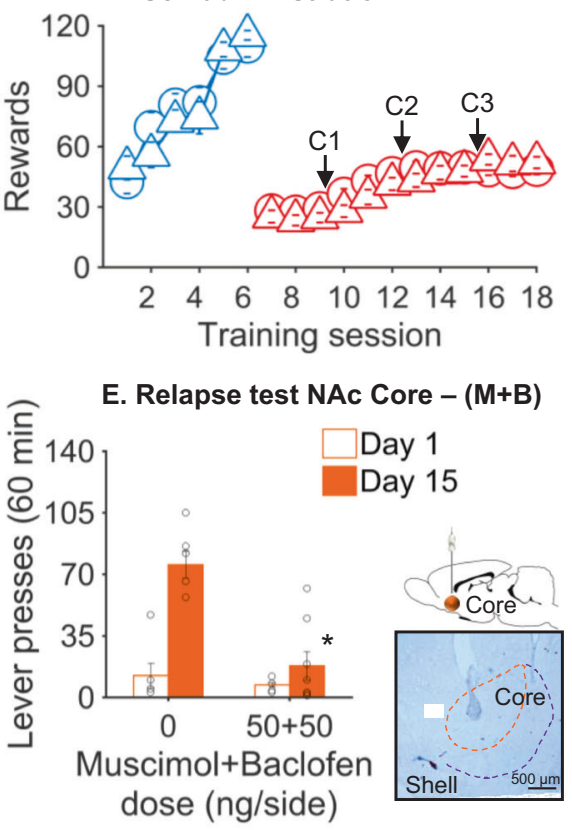

C. Choice test

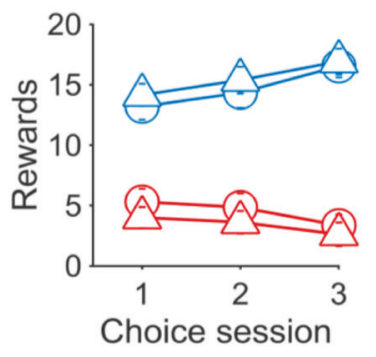

F. Relapse test NAc Shell - (M+B)

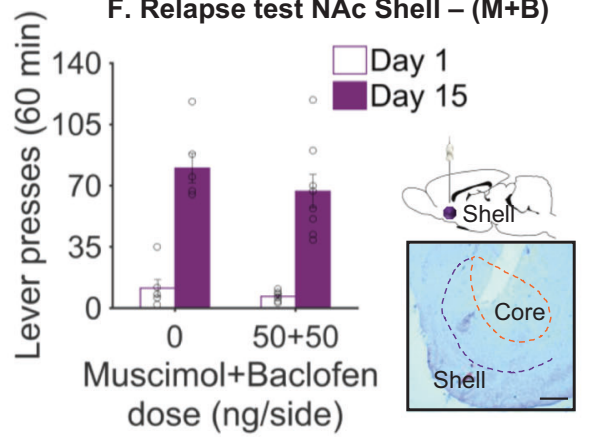

D. Voluntary abstinence

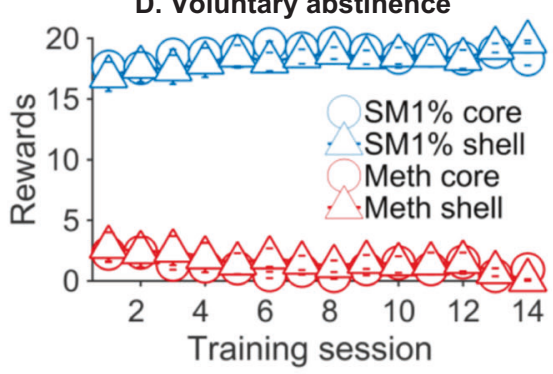

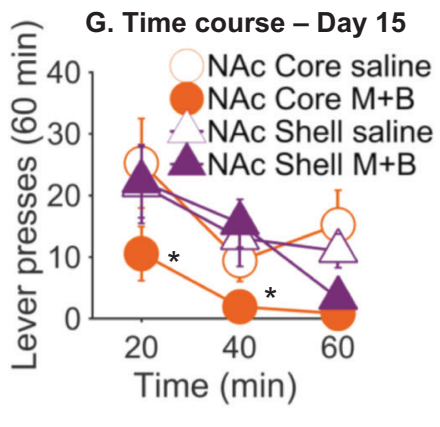

H. Cannula placement - Core

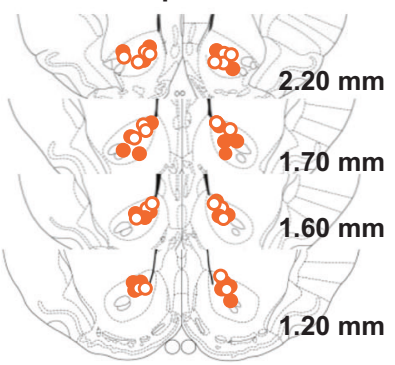

I. Cannula placement - Shell

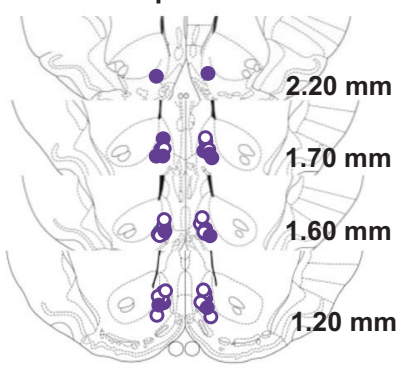

Fig. 2 Reversible inactivation of NAc core but not shell decreased incubated methamphetamine seeking after voluntary abstinence. a Timeline of the experiment (Exp.2). b Self-administration training. Mean \pm SEM number of SM1\% rewards or methamphetamine infusions during the 6-h sessions in rats with implanted cannula in the NAc core (Core) or NAc shell (Shell), $n=52$. c Choice sessions during training. Mean \pm SEM number of SM1\% rewards and methamphetamine infusions earned during the three discrete choice sessions during training in core and shell rats, $n=52$. d Voluntary abstinence. Mean \pm SEM number of SM1\% rewards and methamphetamine infusions earned during 14 discrete choice sessions from the voluntary abstinence group tested on abstinence day $15, n=28$. e, $\mathbf{f}$ Relapse tests for muscimol + baclofen $(M+B)$ injections into NAc core and shell. Mean \pm SEM number of lever presses on active, nonreinforced lever during the $60-m i n$ test sessions on day $1(n=24)$ or day $15(n=28)$ of voluntary abstinence. We injected vehicle or $\mathrm{M}+\mathrm{B}(50 \mathrm{ng}+50 \mathrm{ng} / 0.5 \mu \mathrm{l} / \mathrm{side})$ into NAc core or shell 15 min before the 60-min extinction tests. We added a representative photomicrograph of the cannula placement in the area (scale bar, $500 \mu \mathrm{m}$ ). ${ }^{*} p<0.05$ different from day $1 . \mathbf{g}$ Time course of lever presses during the relapse test on day 15 . Mean \pm SEM number of lever presses on active, nonreinforced lever during different time periods of the relapse test (0-20, 20-40, and 40-60 $\mathrm{min})(n=28)$. $\mathbf{h}$, i Cannula placement in NAc core or shell. Approximate placement (mm from bregma) of the injector tips [80]. Vehicle: open circles; $M+B$ : closed circles)

Methodological considerations

A number of methodological issues should be considered in the interpretation of the present data. The first issue is represented by the specificity of the inactivating effect of muscimol + baclofen on NAc core. It is unlikely that this effect was due to nonspecific performance deficits, as muscimol + baclofen had no effect on lever presses during abstinence day 1 or high-rate operant responding for the palatable solution (sucrose 1\%+ maltodextrin 1\%) (see Results and Figs. 2e-S2C). Similarly, it is unlikely that the effect of SCH39166 and raclopride NAc core injections was due to nonspecific performance deficits. This is because we used a dose that had no effect on operant 


\section{A. Timeline Exp. 3 and 4}

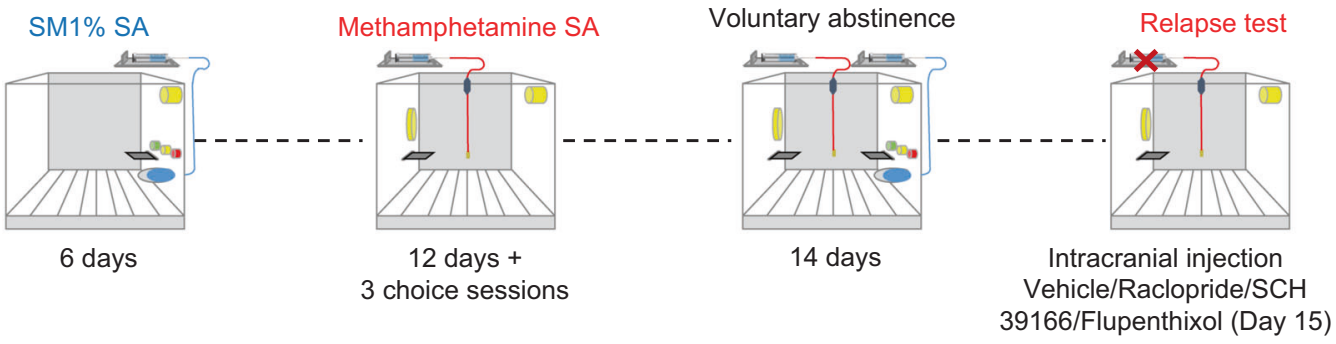

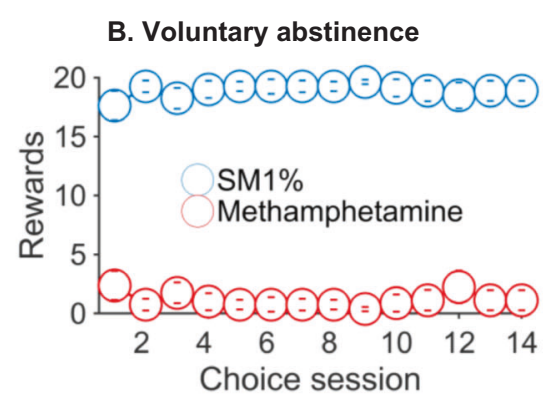

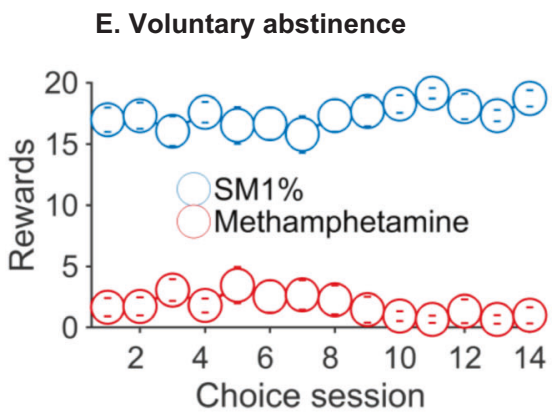

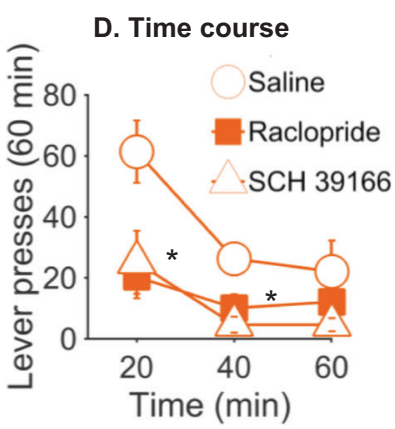
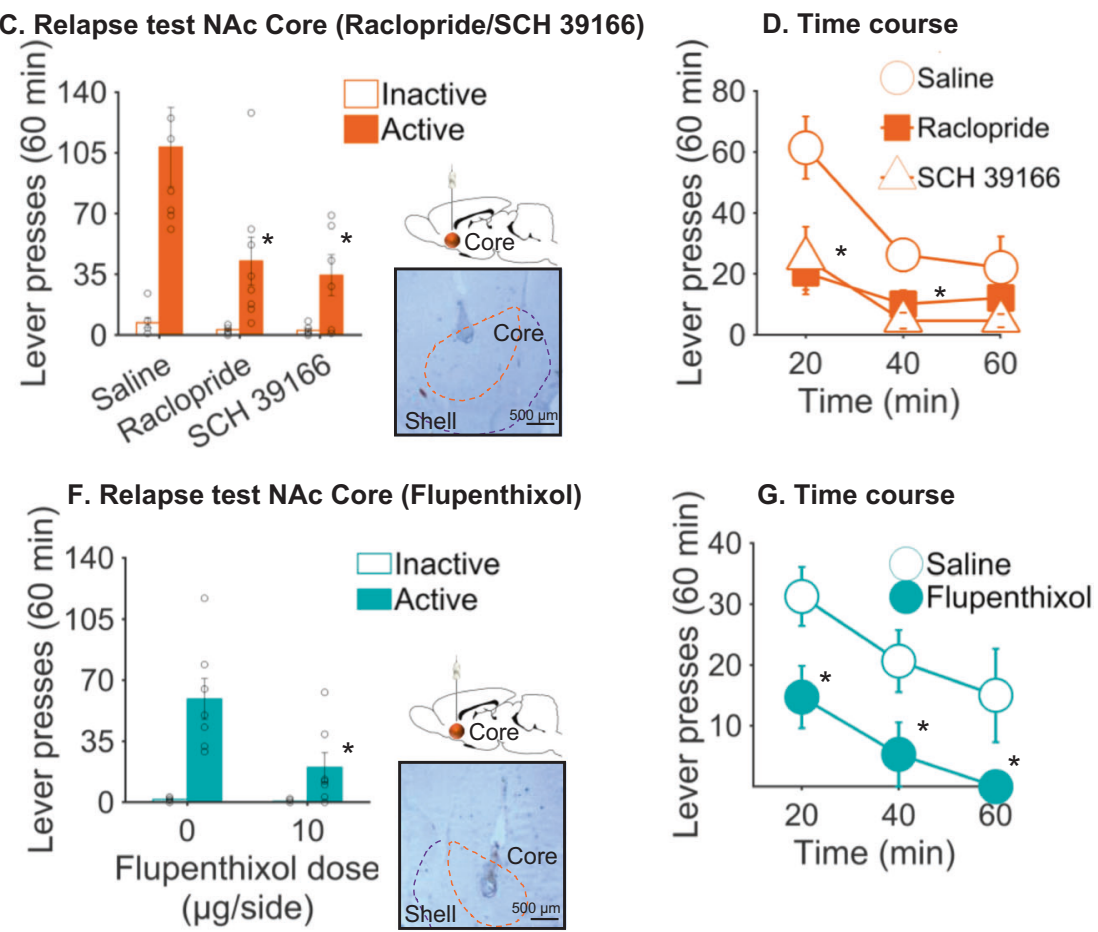

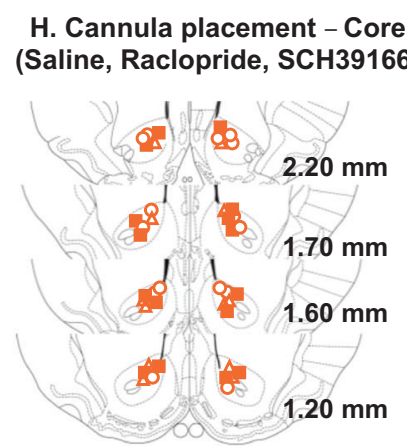

responding for the palatable food (\%) (see Results and Fig. S2E). In this context, it is important to emphasize that depletions of NAc dopamine do not substantially impair all aspects of primary food motivation, and that NAc infusions of dopamine antagonists at doses that impair runway performance did not impair sucrose intake (for reviews [41, 42]).

The second methodological issue is represented by the anatomical specificity of the intracranial injections. It is unlikely that the behavioral changes were due to drug diffusion from the injection site [43], because injections into NAc shell had no effect on incubated methamphetamine craving after food choiceinduced voluntary abstinence (see Results and Fig. 2f). A third methodological consideration is that we used only male rats in this study. In this regard, several studies demonstrated sex
I. Cannula placement - Core (Flupenthixol)

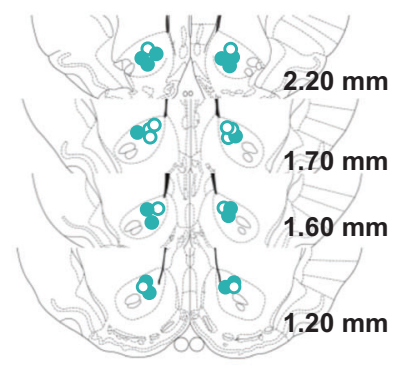

differences in psychostimulant self-administration and relapse, including incubation of cocaine craving after forced abstinence $[44,45]$, and reinstatement of methamphetamine seeking [46]. However, it is unlikely that female rats would have responded differently to our manipulations. In our previous studies, we found no evidence for sex differences in methamphetamine selfadministration, or in the strong preference for the palatable food over methamphetamine or the magnitude of incubated methamphetamine seeking after either forced or voluntary abstinence [11]. The fourth methodological issue concerns the muscimol + baclofen effect on methamphetamine seeking. We only observed an effect of the two agonists on abstinence day 15 but not day 1 , suggesting a selective effect on 'incubated" cue-induced drug seeking. However, this selective time-dependent effect should be 
Fig. 3 Drd1, Drd2, or Drd1-Drd2 antagonists' injection into NAc core decreased relapse after voluntary abstinence. a Timeline of the experiments (Exp.3 and 4). b Voluntary abstinence Exp.3 (raclopride or SCH39166). Mean \pm SEM number of SM1\% rewards and methamphetamine infusions earned during 14 discrete choice sessions. c Relapse test for raclopride or SCH39166 injections into NAc core (Exp.3). Mean \pm SEM number of lever presses on active, nonreinforced, and inactive levers during the 60 -min test sessions on day 15 of voluntary abstinence. We injected vehicle or raclopride $(1.0 \mu \mathrm{g} / 0.5 \mu \mathrm{l} / \mathrm{side})$ or SCH39166 $(1.0 \mu \mathrm{g} / 0.5 \mu \mathrm{l} / \mathrm{side})$ into NAc core $15 \mathrm{~min}$ before the 60 -min extinction tests. We added a representative photomicrograph of the cannula placement in the area (scale bar, $500 \mathrm{~mm}$ ). $\mathbf{d}$ Time course of lever presses during the relapse test on day 15 (Exp.3). Mean \pm SEM number of lever presses on active, nonreinforced lever during different time periods of the relapse test $(0-20,20-40$, and $40-60 \mathrm{~min}$ ). e Voluntary abstinence Exp.4 (flupenthixol). Mean \pm SEM number of SM1\% rewards and methamphetamine infusions earned during 14 discrete choice sessions. f Relapse test for flupenthixol injections into NAc core (Exp.4). Mean \pm SEM number of lever presses on active, nonreinforced, and inactive levers during the 60-min test sessions on day 15 of voluntary abstinence. We injected vehicle or flupenthixol $(10 \mu \mathrm{g} / 0.5 \mu \mathrm{l} / \mathrm{side})$ into NAc core $15 \mathrm{~min}$ before the 60 -min extinction test. We added a representative photomicrograph of the cannula placement in the area (scale bar, $500 \mu \mathrm{m})$. $\mathbf{g}$ Time course of lever presses during the relapse test on day 15 (Exp.4). Mean \pm SEM number of lever presses on active, non-reinforced lever during different time periods of the relapse test (0-20, 20-40, and 40-60-min). h Cannula placement in NAc core (Exp.3). Approximate placement (mm from bregma) of the injector tips [80]. Vehicle: open circles; raclopride: closed squares; SCH39166: open triangles). i Cannula placement in NAc core (Exp.4). Approximate placement

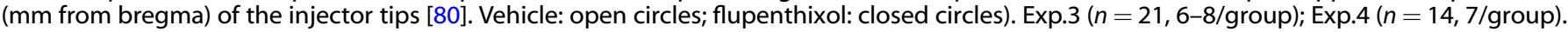
${ }^{*} p<0.05$ different from saline

interpreted with caution because of a potential floor effect due to low responding on day 1.

Finally, from a brain mechanism perspective, we did not investigate the role of dopamine transmission in the NAc shell in the incubation of methamphetamine craving after voluntary abstinence because we did not observe neither a time-dependent increase in Fos expression after the relapse tests on abstinence days 1 and 15 (see Results and Fig. 1g, lower panel) nor an attenuation of incubated craving after the reversible inactivation with muscimol + baclofen (see Results and Fig. 2f). However, these correlational and causal data do not definitively rule out a role of NAc shell dopamine transmission in the incubation of methamphetamine craving because previous studies have demonstrated dissociable effects of reversible inactivation relative to dopamine or glutamate receptors blockade [47].

The role of nucleus accumbens core in incubation of methamphetamine craving after voluntary abstinence The NAC core and shell are heterogeneous structures distinguished on the basis of the morphology and projections [48, 49]. These neuroanatomical evidences stimulated a large number of studies on the role of NAc core and shell in motivated behavior $[50,51]$ and conditioned and unconditioned rewarding effects of drugs $[52,53]$. Our results from Exp. 1 and 2, supporting a role for the NAc core but not shell in incubation of methamphetamine craving after voluntary abstinence, are in agreement with the general notion that NAc core and shell mediate distinct aspects of drug-motivated behaviors [54]. In particular, they are in agreement with previous findings where permanent lesions or reversible inactivation (muscimol + baclofen) of core but not shell decrease discrete-cue-induced reinstatement of cocaine $[55,56]$ and methamphetamine seeking [57] and discrete-cue-induced cocaine seeking, as assessed in an acquisition of a new response procedure [58].

Our results provide further correlational evidences of altered firing in the NAC core during incubation of cocaine craving after forced abstinence [22, 23]. This altered firing is putatively associated with the higher conductance expressed by the $\mathrm{CP}$ AMPARs (homomeric GluA1 receptors) that accumulate in the NAc core over time $[24,59]$. Consistent with these findings, incubated cocaine and methamphetamine craving after forced abstinence was reduced by decreasing CP-AMPARs transmission in NAc core [24-26] or, for cocaine, via weakening the prelimbic cortex to NAC core pathway [27].

Levels of CP-AMPARs are also elevated in the NAc shell after incubation of cocaine craving [27, 29, 31] and CP-AMPARs transmission in the NAc shell play a causal role in incubation of cocaine craving. These latter evidences are at odds with our data. In Exp. 1 (RNAscope ISH for Fos) and Exp. 2 (muscimol + baclofen inactivation) we did not observe any appreciable increase in Fos expression (marker of neuronal activity) nor an appreciable reduction in incubated methamphetamine craving after voluntary abstinence. What may account for this discrepancy? The answer is not straightforward because a direct comparison of our study and Dong et al. studies $[27,31]$ is not possible for two main reasons: (1) we used methamphetamine, while Dong et al. used cocaine. In the case of NAc core, both incubation to cocaine and methamphetamine have been shown to result in CP-AMPARs in the core. However, we do not know if incubation to methamphetamine results in CP-AMPARs in the shell; (2) we used an extended drug-self administration procedure for 12 days $(6 \mathrm{~h} /$ day) and voluntary abstinence in adult rats, while Dong et al. used a single overnight training session plus short-access procedure for 5 days ( $2 \mathrm{~h} /$ day) and forced abstinence in juvenile rats. It is well established that the neural adaptions occurring during an extended-access relative to short-access self-administration are distinct [60] and that juvenile onset and adult onset selfadministration are associated with different physiological and behavioral changes [61, 62].

Finally, the neuroanatomical substrates responsible for the expression of incubated methamphetamine craving, identified in this (NAc core but not shell) and previous studies (CeA but not BLA; $[20,63])$, mirror the neuroanatomical substrates involved in the expression of the 'general' form of Pavlovian to Instrumental Transfer (PIT) [64], which is thought to represent the general motivational or affective properties of the reward [65]. First proposed by Li et al. [63], our findings support the hypothesis that incubation of drug craving may be due to time-dependent increases in the motivational potency of Pavlovian drug associated cues after abstinence that is mediated by increased activity of CeA and NAc core during the late abstinence relapse tests. The common role of $\mathrm{CeA}[20,63]$ and NAc core in promoting incubation of methamphetamine craving suggests that these regions, with no direct anatomical connections [66] interact functionally during the drug seeking test. As previously speculated for PIT [64], the CeA may indirectly recruit the NAc core via its projections to ventral tegmental area, which projects to NAC core [66].

Role of NAc Drd1- and Drd2-MSNs during incubation of methamphetamine-craving after voluntary abstinence

The mesolimbic dopamine system innervating the NAc is critically involved in cue-elicited reinstatement of drug seeking [67]. However, relatively little is known on the role of NAc-dopamine transmission in incubation of cue-induced drug craving after prolonged forced and voluntary abstinence. Ito et al., [68] first reported that cocaine-associated cues significantly increase extracellular dopamine in the NAc core (see Willuhn for a review and conflicting findings [69]), suggesting that enhanced dopamine transmission may be involved in cue-induced craving and relapse 
to drug seeking. Subsequently, a seminal study by Ciccocioppo et al. [70], showed that systemic blockade of Drd1 decreases both discriminative cue-induced reinstatement and discriminative cueinduced Fos, and that the reinstatement effect of the discriminative cues persists for at least 4 months after cocaine exposure [70]. These investigators also demonstrated that the response to the cocaine-associated discriminative cues is remarkably persistent over repeated testing and that Drd2 play a role in this form of reinstatement [71]. Since then, several studies employing Drd1 and Drd2 partial agonists and antagonists have been shown to reduce cue-induced drug seeking (reviewed in [72]).

Overall, the effect of selective Drd1 and Drd2 (SCH39166 and raclopride) or both Drd1-Drd2 (flupenthixol) antagonists reported here confirm earlier findings and suggest that the incubation of methamphetamine seeking after voluntary abstinence is not dependent of a specific subtype of MSNs. Furthermore, our data do not support the hypothesis that Drd1 and Drd2 MSNs act in opposing manner [73] but rather, suggests that a coincident and concerted MSNs activity is required for reward-related behaviors [74-76]. Indeed, regardless of the antagonist used in our experiments (SCH39166, Drd1-selective; raclopride, Drd2-selective; flupenthixol, Drd1-Drd2-selective), we observed reliable reduction of incubation of methamphetamine craving.

Our data are also consistent with our previous results on incubation of methamphetamine seeking after forced and voluntary abstinence. Indeed, in these studies the incubation-sensitive Fos-positive neurons (activated after periods of forced or voluntary abstinence) in the dorsomedial and dorsolateral striatum coexpressed both Drd1 and Drd2 [10, 77]. Furthermore, studies employing extended-access cocaine regimens leading to incubation of cocaine craving support the idea that there is a similar plasticity in Drd1- and Drd2-expressing MSNs in NAc core [78] or even in the dorsal striatum [79]. An important example is the elevation of CP-AMPAR levels that is observed in nearly all NAc core MSNs after extended-access cocaine self-administration and after a month of abstinence, albeit in a pathway-specific manner [59, 78].

\section{CONCLUSIONS}

We used our recently developed choice-based rat model of drug relapse after voluntary abstinence that mimics the human condition of relapse after successful contingency management. Here we used RNAscope ISH and pharmacological approaches to show a critical role of Drd1- and Drd2-mediated NAC core neuronal activity in the expression of incubation of methamphetamine craving after food choice-induced voluntary abstinence.

To the degree that our choice-based model of drug relapse in rats mimics the human condition of relapse after successful contingency management, our findings suggest the NAc core as a potential target for relapse prevention.

\section{FUNDING AND DISCLOSURE}

The research was supported by funding from the Department of Physiology and Pharmacology of Sapienza University (Development Fund 000126-2017 to DC) and from Sapienza University (Fondi di Ateneo RM11715C457665A to DC) and by the NIDA Drug Supply Program. We thank Dr. Yavin Shaham for his comments on an earlier version of this paper. The authors declare no competing interests.

\section{ADDITIONAL INFORMATION}

Supplementary Information accompanies this paper at (https://doi.org/10.1038/ s41386-019-0479-4).

Publisher's note: Springer Nature remains neutral with regard to jurisdictional claims in published maps and institutional affiliations.

\section{REFERENCES}

1. Preston $\mathrm{KL}$, Umbricht $\mathrm{A}$, Epstein $\mathrm{DH}$. Abstinence reinforcement maintenance contingency and one-year follow-up. Drug alcohol Depend. 2002;67:125-37.

2. Stitzer $M$, Jones HE, Tuten $M$, Wong $C$. Goal-based approaches to assessment and intervention with addiction and other problems. In: WM Cox, E Klinger, editors. Handbook of motivational counseling. Chichester, UK: John Wiley \& Sons; 2011.

3. Higgins ST, Delaney DD, Budney AJ, Bickel WK, Hughes JR, Foerg F, et al. A behavioral approach to achieving initial cocaine abstinence. Am J Psychiatry. 1991;148:1218-24.

4. Roll JM. Contingency management: an evidence-based component of methamphetamine use disorder treatments. Addiction. 2007;102(Suppl 1):114-20.

5. Heilig M, Epstein DH, Nader MA, Shaham Y. Time to connect: bringing social context into addiction neuroscience. Nat Rev Neurosci. 2016;17:592-9.

6. Lenoir M, Serre F, Cantin L, Ahmed SH. Intense sweetness surpasses cocaine reward. PLoS One. 2007;2:e698.

7. Ahmed SH, Lenoir M, Guillem K. Neurobiology of addiction versus drug use driven by lack of choice. Curr Opin Neurobiol. 2013;23:581-7.

8. Caprioli D, Venniro M, Zeric T, Li X, Adhikary S, Madangopal R, et al. Effect of the novel positive allosteric modulator of metabotropic glutamate receptor 2 AZD8529 on incubation of methamphetamine craving after prolonged voluntary abstinence in a rat model. Biol Psychiatry. 2015;78:463-73.

9. Caprioli D, Zeric T, Thorndike EB, Venniro M. Persistent palatable food preference in rats with a history of limited and extended access to methamphetamine selfadministration. Addict Biol. 2015;20:913-26.

10. Caprioli D, Venniro M, Zhang M, Bossert JM, Warren BL, Hope BT, et al. Role of dorsomedial striatum neuronal ensembles in incubation of methamphetamine craving after voluntary abstinence. J Neurosci. 2017;37:1014-27.

11. Venniro M, Zhang M, Shaham Y, Caprioli D. Incubation of methamphetamine but not heroin craving after voluntary abstinence in male and female rats. Neuropsychopharmacology. 2017;42:1126-35.

12. Grimm JW, Hope BT, Wise RA, Shaham Y. Neuroadaptation. Incubation of cocaine craving after withdrawal. Nature. 2001;412:141-2.

13. Pickens $C L$, Airavaara M, Theberge F, Fanous $S$, Hope BT, Shaham Y. Neurobiology of the incubation of drug craving. Trends Neurosci. 2011;34:411-20.

14. Venniro M, Caprioli D, Shaham Y. Animal models of drug relapse and craving: from drug priming-induced reinstatement to incubation of craving after voluntary abstinence. Prog Brain Res. 2016;224:25-52.

15. Bedi G, Preston KL, Epstein DH, Heishman SJ, Marrone GF, Shaham Y, et al. Incubation of cue-induced cigarette craving during abstinence in human smokers. Biol psychiatry. 2011;69:708-11.

16. Wang G, Shi J, Chen N, Xu L, Li J, Li P, et al. Effects of length of abstinence on decision-making and craving in methamphetamine abusers. PLoS One. 2013;8: e68791.

17. Li $P$, Wu $P$, Xin $X$, Fan $Y L$, Wang GB, Wang $F$, et al. Incubation of alcohol craving during abstinence in patients with alcohol dependence. Addict Biol. 2015;20: 513-22.

18. Bach P, Bumb JM, Schuster R, Vollstadt-Klein S, Reinhard I, Rietschel M, et al. Effects of leptin and ghrelin on neural cue-reactivity in alcohol addiction: two streams merge to one river? Psychoneuroendocrinology. 2019;100:1-9.

19. Parvaz MA, Moeller SJ, Goldstein RZ. Incubation of cue-induced craving in adults addicted to cocaine measured by electroencephalography. JAMA Psychiatry. 2016;73:1127-34.

20. Venniro M, Caprioli D, Zhang M, Whitaker LR, Zhang S, Warren BL, et al. The anterior insular cortex->central amygdala glutamatergic pathway is critical to relapse after contingency management. Neuron. 2017;96:414-27 e8.

21. Gerfen CR, Surmeier DJ. Modulation of striatal projection systems by dopamine. Annu Rev Neurosci. 2011;34:441-66.

22. Hollander JA, Carelli RM. Abstinence from cocaine self-administration heightens neural encoding of goal-directed behaviors in the accumbens. Neuropsychopharmacology. 2005;30:1464-74.

23. Guillem K, Ahmed SH, Peoples LL. Escalation of cocaine intake and incubation of cocaine seeking are correlated with dissociable neuronal processes in different accumbens subregions. Biol Psychiatry. 2014;76:31-9.

24. Conrad KL, Tseng KY, Uejima JL, Reimers JM, Heng LJ, Shaham Y, et al. Formation of accumbens GluR2-lacking AMPA receptors mediates incubation of cocaine craving. Nature. 2008;454:118-21.

25. Loweth JA, Scheyer AF, Milovanovic M, LaCrosse AL, Flores-Barrera E, Werner CT, et al. Synaptic depression via mGluR1 positive allosteric modulation suppresses cue-induced cocaine craving. Nat Neurosci. 2014;17:73-80.

26. Scheyer AF, Loweth JA, Christian DT, Uejima J, Rabei R, Le T, et al. AMPA receptor plasticity in accumbens core contributes to incubation of methamphetamine craving. Biol Psychiatry. 2016;80:661-70.

27. Ma YY, Lee BR, Wang X, Guo C, Liu L, Cui R, et al. Bidirectional modulation of incubation of cocaine craving by silent synapse-based remodeling of prefrontal cortex to accumbens projections. Neuron. 2014;83:1453-67. 
28. Terrier J, Luscher C, Pascoli V. Cell-type specific insertion of GluA2-lacking AMPARs with cocaine exposure leading to sensitization, cue-induced seeking, and incubation of craving. Neuropsychopharmacology. 2016;41:1779-89.

29. McCutcheon JE, Wang X, Tseng KY, Wolf ME, Marinelli M. Calcium-permeable AMPA receptors are present in nucleus accumbens synapses after prolonged withdrawal from cocaine self-administration but not experimenter-administered cocaine. J Neurosci. 2011;31:5737-43.

30. Mameli M, Halbout B, Creton C, Engblom D, Parkitna JR, Spanagel R, et al. Cocaine-evoked synaptic plasticity: persistence in the VTA triggers adaptations in the NAc. Nat Neurosci. 2009;12:1036-41.

31. Lee BR, Ma YY, Huang YH, Wang X, Otaka M, Ishikawa $M$, et al. Maturation of silent synapses in amygdala-accumbens projection contributes to incubation of cocaine craving. Nat Neurosci. 2013;16:1644-51.

32. Pascoli V, Terrier J, Espallergues J, Valjent E, O'Connor EC, Luscher C. Contrasting forms of cocaine-evoked plasticity control components of relapse. Nature. 2014;509:459-64.

33. Venniro M, Zhang M, Caprioli D, Hoots JK, Golden SA, Heins $C$, et al. Volitional social interaction prevents drug addiction in rat models. Nat Neurosci. 2018;21:1520-29.

34. Morgan Jl, Curran T. Stimulus-transcription coupling in the nervous system: involvement of the inducible proto-oncogenes fos and jun. Annu Rev Neurosci. 1991;14:421-51.

35. McFarland K, Kalivas PW. The circuitry mediating cocaine-induced reinstatement of drug-seeking behavior. J Neurosci. 2001;21:8655-63.

36. Delfs JM, Schreiber L, Kelley AE. Microinjection of cocaine into the nucleus accumbens elicits locomotor activation in the rat. J Neurosci. 1990;10:303-10.

37. Chipkin RE, lorio LC, Coffin VL, McQuade RD, Berger JG, Barnett A. Pharmacological profile of SCH39166: a dopamine D1 selective benzonaphthazepine with potential antipsychotic activity. J Pharmacol Exp Ther. 1988;247:1093-102.

38. Kohler C, Hall H, Ogren SO, Gawell L. Specific in vitro and in vivo binding of $3 \mathrm{H}-$ raclopride. A potent substituted benzamide drug with high affinity for dopamine D-2 receptors in the rat brain. Biochem Pharmacol. 1985;34:2251-59.

39. Curran T, Morgan Jl. Fos: an immediate-early transcription factor in neurons. J Neurobiol. 1995;26:403-12.

40. Golden SA, Jin M, Heins C, Venniro M, Michaelides M, Shaham Y. Nucleus accumbens Drd1-expressing neurons control aggression self-administration and aggression seeking in mice. J Neurosci. 2019;39:2482-96.

41. Salamone JD, Correa M. Motivational views of reinforcement: implications for understanding the behavioral functions of nucleus accumbens dopamine. Behav Brain Res. 2002;137:3-25.

42. Ikemoto $S$, Panksepp J. The role of nucleus accumbens dopamine in motivated behavior: a unifying interpretation with special reference to reward-seeking. Brain Res Rev. 1999:31:6-41.

43. Wise RA, Hoffman DC. Localization of drug reward mechanisms by intracranial injections. Synapse. 1992;10:247-63.

44. Kerstetter KA, Aguilar VR, Parrish AB, Kippin TE. Protracted time-dependent increases in cocaine-seeking behavior during cocaine withdrawal in female relative to male rats. Psychopharmacology. 2008;198:63-75.

45. Nicolas C, Russell TI, Pierce AF, Maldera S, Holley A, You ZB, et al. Incubation of cocaine craving after intermittent access self-administration: sex differences and estrous cycle. Biol Psychiatry. 2019;85:915-24.

46. Cox BM, Young AB, See RE, Reichel CM. Sex differences in methamphetamine seeking in rats: impact of oxytocin. Psychoneuroendocrinology. 2013;38:2343-53.

47. Bossert JM, Marchant NJ, Calu DJ, Shaham Y. The reinstatement model of drug relapse: recent neurobiological findings, emerging research topics, and translational research. Psychopharmacology. 2013;229:453-76.

48. Voorn P, Gerfen CR, Groenewegen HJ. Compartmental organization of the ventral striatum of the rat: immunohistochemical distribution of enkephalin, substance $P$, dopamine, and calcium-binding protein. J Comp Neurol. 1989;289:189-201.

49. Zahm DS, Brog JS. On the significance of subterritories in the "accumbens" part of the rat ventral striatum. Neuroscience. 1992;50:751-67.

50. Cardinal RN, Parkinson JA, Lachenal G, Halkerston KM, Rudarakanchana N, Hall J, et al. Effects of selective excitotoxic lesions of the nucleus accumbens core, anterior cingulate cortex, and central nucleus of the amygdala on autoshaping performance in rats. Behav Neurosci 2002;116:553-67.

51. Kelley $A E$. Ventral striatal control of appetitive motivation: role in ingestive behavior and reward-related learning. Neurosci Biobehav Rev. 2004;27:765-76.

52. Everitt BJ, Wolf ME. Psychomotor stimulant addiction: a neural systems perspective. Neurosci. 2002;22:3312-20.

53. Ikemoto S, Wise RA. Mapping of chemical trigger zones for reward. Neuropharmacology. 2004;47(Suppl 1):190-201.

54. Everitt BJ, Robbins TW. Neural systems of reinforcement for drug addiction: from actions to habits to compulsion. Nat Neurosci. 2005;8:1481-9.
55. Di Ciano P, Cardinal RN, Cowell RA, Little SJ, Everitt BJ. Differential involvement of NMDA, AMPA/kainate, and dopamine receptors in the nucleus accumbens core in the acquisition and performance of pavlovian approach behavior. J Neurosci. 2001;21:9471-7.

56. Fuchs RA, Evans KA, Parker MC, See RE. Differential involvement of the core and shell subregions of the nucleus accumbens in conditioned cue-induced reinstatement of cocaine seeking in rats. Psychopharmacology. 2004;176:459-65.

57. Rocha A, Kalivas PW. Role of the prefrontal cortex and nucleus accumbens in reinstating methamphetamine seeking. Eur J Neurosci. 2010;31:903-9.

58. Di Ciano P, Robbins TW, Everitt BJ. Differential effects of nucleus accumbens core, shell, or dorsal striatal inactivations on the persistence, reacquisition, or reinstatement of responding for a drug-paired conditioned reinforcer. Neuropsychopharmacology. 2008;33:1413-25.

59. Wolf ME. Synaptic mechanisms underlying persistent cocaine craving. Nat Rev Neurosci. 2016;17:351-65.

60. Ahmed SH, Kenny PJ. Cracking the molecular code of cocaine addiction. ILAR J. 2011;52:309-20.

61. Counotte DS, Schiefer C, Shaham Y, O'Donnell P. Time-dependent decreases in nucleus accumbens AMPA/NMDA ratio and incubation of sucrose craving in adolescent and adult rats. Psychopharmacology. 2014;231:1675-84.

62. Li C, Frantz KJ. Attenuated incubation of cocaine seeking in male rats trained to selfadminister cocaine during periadolescence. Psychopharmacology. 2009;204:725-33.

63. Li X, Zeric T, Kambhampati S, Bossert JM, Shaham Y. The central amygdala nucleus is critical for incubation of methamphetamine craving. Neuropsychopharmacology. 2015;40:1297-306.

64. Hall J, Parkinson JA, Connor TM, Dickinson A, Everitt BJ. Involvement of the central nucleus of the amygdala and nucleus accumbens core in mediating Pavlovian influences on instrumental behaviour. Eur J Neurosci. 2001;13:1984-92.

65. Corbit LH, Balleine BW. Double dissociation of basolateral and central amygdala lesions on the general and outcome-specific forms of pavlovian-instrumental transfer. J Neurosci. 2005;25:962-70.

66. Price JL, Amaral DG. An autoradiographic study of the projections of the central nucleus of the monkey amygdala. J Neurosci. 1981;1:1242-59.

67. Shalev U, Grimm JW, Shaham Y. Neurobiology of relapse to heroin and cocaine seeking: a review. Pharmacol Rev. 2002;54:1-42.

68. Ito R, Dalley JW, Howes SR, Robbins TW, Everitt BJ. Dissociation in conditioned dopamine release in the nucleus accumbens core and shell in response to cocaine cues and during cocaine-seeking behavior in rats. J Neurosci. 2000;20:7489-95.

69. Willuhn I, Wanat MJ, Clark JJ, Phillips PE. Dopamine signaling in the nucleus accumbens of animals self-administering drugs of abuse. Curr Top Behav Neurosci. 2010;3:29-71.

70. Ciccocioppo R, Sanna PP, Weiss F. Cocaine-predictive stimulus induces drug-seeking behavior and neural activation in limbic brain regions after multiple months of abstinence: reversal by D(1) antagonists. Proc Natl Acad Sci USA. 2001;98:1976-81.

71. Weiss F, Martin-Fardon R, Ciccocioppo R, Kerr TM, Smith DL, Ben-Shahar O. Enduring resistance to extinction of cocaine-seeking behavior induced by drugrelated cues. Neuropsychopharmacology. 2001;25:361-72.

72. Galaj E, Ewing S, Ranaldi R. Dopamine D1 and D3 receptor polypharmacology as a potential treatment approach for substance use disorder. Neurosci Biobehav Rev. 2018;89:13-28.

73. Lobo MK, Nestler EJ. The striatal balancing act in drug addiction: distinct roles of direct and indirect pathway medium spiny neurons. Front Neuroanat. 2011;5:41.

74. Cole SL, Robinson MJF, Berridge KC. Optogenetic self-stimulation in the nucleus accumbens: D1 reward versus D2 ambivalence. PLoS One. 2018;13:e0207694.

75. Soares-Cunha C, Coimbra B, David-Pereira A, Borges S, Pinto L, Costa P, et al. Activation of D2 dopamine receptor-expressing neurons in the nucleus accumbens increases motivation. Nat Commun. 2016;7:11829.

76. Francis TC, Yano H, Demarest TG, Shen H, Bonci A. High-frequency activation of nucleus accumbens D1-MSNs drives excitatory potentiation on D2-MSNs. Neuron. 2019:103:432-44.e3.

77. Li X, Rubio FJ, Zeric T, Bossert JM, Kambhampati S, Cates HM, et al. Incubation of methamphetamine craving is associated with selective increases in expression of Bdnf and trkb, glutamate receptors, and epigenetic enzymes in cue-activated fosexpressing dorsal striatal neurons. J Neurosci. 2015;35:8232-44.

78. Wolf ME, Tseng KY. Calcium-permeable AMPA receptors in the VTA and nucleus accumbens after cocaine exposure: when, how, and why? Front Mol Neurosci. 2012;5:72.

79. Li X, Witonsky KR, Lofaro OM, Surjono F, Zhang J, Bossert JM, et al. Role of anterior intralaminar nuclei of thalamus projections to dorsomedial striatum in incubation of methamphetamine craving. J Neurosci. 2018;38:2270-82.

80. Paxinos G, Watson C. The rat brain in stereotaxic coordinates. 6th ed. San Diego, CA: Academic Press; 2007. 